echocardiographic analysis, her pulmonary arterial systolic pressure had decreased to $34 \mathrm{~mm} \mathrm{Hg}$, and left ventricular ejection fraction had increased to $55 \%$. There was only trace tricuspid valve regurgitation.

\section{DISCUSSION}

The patient described had parietal pericardial bovine bioprostheses in both the mitral and aortic valve positions for 77 months and during that period developed huge quantities of calcium on the cusps of the bioprosthesis in the aortic valve position and only small quantities of calcium on the cusps of the bioprosthesis in the mitral valve position. Because the closing pressure on the mitral bioprosthesis is usually about a third higher than that on the aortic bioprosthesis (peak left ventricular systolic pressure vs end-diastolic aortic pressure; normally approximately $120 \mathrm{vs} 80 \mathrm{~mm} \mathrm{Hg}$ ), it might be expected that the degeneration of a bioprosthesis in the mitral position would be greater (more calcium and more tears) and more rapid than that of a bioprosthesis in the aortic position, but the opposite was the case in the patient described herein. Why might that be the case? Some possibilities include the following:

1. Parietal pericardial bovine bioprostheses are not the same as porcine aortic valve bioprostheses. The former are thicker and less flexible and possibly withstand the left ventricular peak systolic pressure and the aortic end-dia- stolic pressure more easily than the more delicate porcine aortic cusps.

2. The bovine bioprosthesis in the aortic position was defective and not properly prepared, whereas the one in the mitral position was not.

3. The febrile illness the patient had beginning 11 months after the initial cardiac operation could have been active infective endocarditis that affected the bioprosthesis in the aortic position but not the bioprosthesis in the mitral position.

4. Smaller bovine parietal pericardial bioprostheses calcify more rapidly and more extensively than do larger bovine pericardial bioprostheses.

5. The paravalvular leak in the mitral position and the absence of a leak in the aortic position provided a "bypass shunt," diminishing the effect of the full force of the peak left ventricular systolic pressure on the bioprosthetic cusps in the mitral position.

None of these 5 possibilities can be proved or disproved, but this report might stimulate careful follow-up of similar patients to determine whether this distribution of calcium in the 2 left-sided bioprostheses is a pattern or an exception.

\section{Reference}

1. Warnes CA, Scott ML, Silver GM, Smith CW, Ferrans VJ, Roberts WC. Comparison of late degenerative changes in porcine bioprostheses in the mitral and aortic valve position in the same patient. Am J Cardiol. 1983;51:965-8.

\title{
Is minimized extracorporeal circulation effective to reduce the need for red blood cell transfusion in coronary artery bypass grafting? Meta-analysis of randomized controlled trials
}

\author{
Umberto Benedetto, MD, Emiliano Angeloni, MD, Simone Refice, MD, Fabio Capuano, MD, \\ Massimo Goracci, MD, Antonino Roscitano, MD, and Riccardo Sinatra, MD, Rome, Italy
}

From the Cardiac Surgery Department, II School of Medicine, University of Rome La Sapienza, Policlinico S. Andrea, Rome, Italy.

Received for publication Dec 2, 2008; accepted for publication March 23, 2009; available ahead of print May 25, 2009.

Address for reprints: Umberto Benedetto, MD, Cardiac Surgery Department, II School of Medicine, University of Rome “La Sapienza,' Via di Grottarossa 1039 (E-mail: u2benedetto@libero.it).

J Thorac Cardiovasc Surg 2009;138:1450-3

$0022-5223 / \$ 36.00$

Copyright (C) 2009 by The American Association for Thoracic Surgery

doi:10.1016/j.jtcvs.2009.03.042
Perioperative red blood cell (RBC) transfusion is the single factor most consistently associated with an increased risk of postoperative morbid events after isolated coronary artery bypass grafting (CABG), and each unit of RBC transfused is associated with incrementally increased risk for adverse outcome. ${ }^{1}$ Miniaturized extracorporeal circulation (miniECC) has been proposed to limit perioperative blood product use. Mini-ECC consists of a closed ECC system with no cardiotomy suction or venous reservoir. The rationale is to avoid air blood contact and minimize priming volume, thus reducing hemostasis alteration and intraoperative 
TABLE 1. Randomized controlled trials enrolled

\begin{tabular}{|c|c|c|c|}
\hline First author & Publication & $\begin{array}{c}\text { Mini-ECC } \\
\text { no. of } \\
\text { patients } \\
\end{array}$ & $\begin{array}{c}\text { Conventional } \\
\text { ECC } \\
\text { no. of patients } \\
\end{array}$ \\
\hline Abdel Rahman ${ }^{3}$ & $\begin{array}{l}\text { Ann Thorac Surg. } \\
2005 ; 80: 23844\end{array}$ & 101 & 103 \\
\hline Beghi $^{4}$ & $\begin{array}{l}\text { Ann Thorac Surg. } \\
\text { 2006;81:1396 } 400\end{array}$ & 30 & 30 \\
\hline Huybregts $^{2}$ & $\begin{array}{l}\text { Ann Thorac Surg. } \\
\text { 2007;83:1760 } 7\end{array}$ & 25 & 24 \\
\hline Kamiya $^{5}$ & $\begin{array}{l}\text { Interact Cardiovasc } \\
\text { Thorac Surg. } \\
\text { 2006;5:680 } 2\end{array}$ & 10 & 10 \\
\hline Kofidis $^{6}$ & $\begin{array}{l}\text { Perfusion. 2008; } \\
\text { 23:147 } 51\end{array}$ & 50 & 30 \\
\hline Liebold $^{7}$ & $\begin{array}{c}\text { J Thorac Cardiovasc Surg. } \\
\text { 2006;131:268 } 76\end{array}$ & 20 & 20 \\
\hline Ohata $^{8}$ & ASAIO J. 2008;54:207 9 & 34 & 64 \\
\hline Perthel $^{9}$ & $\begin{array}{l}\text { Eur J Cardiothorac Surg. } \\
\text { 2007;31:1070 } 5\end{array}$ & 30 & 30 \\
\hline Remadi $^{10}$ & $\begin{array}{c}\text { Am Heart J. 2006; } \\
\text { 151:198.e1 e7 }\end{array}$ & 200 & 200 \\
\hline Skrabal $^{11}$ & $\begin{array}{l}\text { J Thorac Cardiovasc } \\
\quad \text { Surg. 2006;132:291 } 6\end{array}$ & 10 & 10 \\
\hline Wippermann $^{12}$ & $\begin{array}{l}\text { Eur J Cardiothorac } \\
\quad \text { Surg. 2005;28:127 } 32\end{array}$ & 10 & 10 \\
\hline
\end{tabular}

ECC, Extracorporeal circulation.

hemodilution. However, there is still controversy on whether such a strategy effectively reduces postoperative RBC transfusion, with some reports showing no evident benefit.

We conducted a meta-analysis on available randomized controlled trials (RCTs) to evaluate whether mini-ECC decreases the risk of postoperative RBC transfusion compared with conventional ECC in patients undergoing CABG.

\section{MATERIALS AND METHODS}

All RCTs comparing results of isolated CABG on mini ECC versus conventional ECC were identified using a 2 level search strategy. First, a public domain database (MEDLINE) was searched using a Web based search engine (PubMed). Second, relevant studies were identified through a manual search of secondary sources, including references of initially identified articles and a search of reviews and commentaries. The MED LINE database was searched from January 1966 to June 2008. MeSH key words included "coronary artery bypass, mini extracorporeal circulation, mini cardiopulmonary bypass" and "randomized controlled trials." Stud ies considered for inclusion ${ }^{2} 12$ met the following criteria: The design was an RCT, the patients were randomly assigned to mini ECC versus conven tional ECC CABG, and the study reported the postoperative RBC transfu sion rate or the amount of RBCs transfused per patient. When several RCTs reported on the same patient material, only the most recent article was included.

Two reviewers (U.B. and E.A.) independently abstracted the data. For each study, data regarding postoperative RBC transfusion rate were used to generate risk difference; data regarding the amount of RBCs transfused per patient were used to generate unbiased Hedges' g $(<0$ favors mini ECC; $>0$ favors conventional ECC). The $95 \%$ confidence intervals (CIs) were based on the asymptotic normality of the combined estimates. Publication bias was evaluated using the Begg and Mazumdar rank cor relation test. The pooled summary effect estimate was calculated by means of a fixed effect model. $I^{2}$ values were evaluated to assess hetero geneity, and a value greater than $50 \%$ was considered as indicative of heterogeneity. Meta regression (method of moments) was used to deal with the possibility of effect modification by patient risk profile (including age, female gender, number of grafts, ECC time) on the study estimates of effect size.

\section{RESULTS}

Our research identified 11 RCTs (including 1051 patients) that compared mini-ECC $(\mathrm{n}=520)$ with conventional ECC $(\mathrm{n}=531) \mathrm{CABG}$ and that reported the RBC transfusion rate or the amount of RBC transfused per patient (Table 1).

Pooled analysis showed that mini-ECC decreased the risk of RBC transfusion (risk difference, $-0.10 ; 95 \% \mathrm{CI},-0.15$ to $-0.005 ; P<.0001)$ and the amount of RBC transfused per patient (Hedges' $\mathrm{g},-0.25$; $95 \% \mathrm{CI},-0.428$ to $-0.07 ; P=$ .005) (Figure 1).

Heterogeneity was absent for the RBC transfusion rate $\left(I^{2}=39 \%\right)$ but not for the amount of RBC transfused per patient $\left(I^{2}=78 \%\right)$. The number of grafts $(\beta=-0.09 ; P=$ $.01)$ and ECC time $(\beta=-0.005 ; P=.01)$ but not age $(P=.42)$ and female gender $(P=.96)$ influenced effect size estimates. No publication bias was found for postoperative $\mathrm{RBC}$ transfusion rate $(P=.50)$ and the amount of $\mathrm{RBC}$ transfused per patient $(P=.22)$.

\section{DISCUSSION}

Mini-ECC has been proposed to reduce postoperative RBC transfusion when compared with conventional ECC. However, among available RCTs, 7 of 11 failed to show a significant benefit. The present analysis, pooling data from RCTs, demonstrated an absolute risk reduction of $\mathrm{RBC}$ transfusion in patients receiving mini-ECC. In addition, this advantage was more evident as the complexity of procedure increased (higher number of grafts performed and prolonged ECC time). The lack of a significant benefit in some RCTs may be partially explained by their limited sample size. Because blood transfusion is reduced by approximately $30 \%$ with a lower priming volume, ${ }^{2}$ the appropriate sample size should be at least 20 patients for each arm to obtain a study power of 0.80 . Of note, 3 of 7 RCTs showing no advantages had only 10 patients for each arm. Abdel-Rahman and colleagues ${ }^{3}$ observed no benefit in study with a large sample size. The authors used a heparin-uncoated minimized circuit that is no longer commercially available, and the latest mini-ECC systems with a fully heparin-coated closed circuit are associated with reduced hemostasis alterations secondary to blood contact with artificial surfaces. 


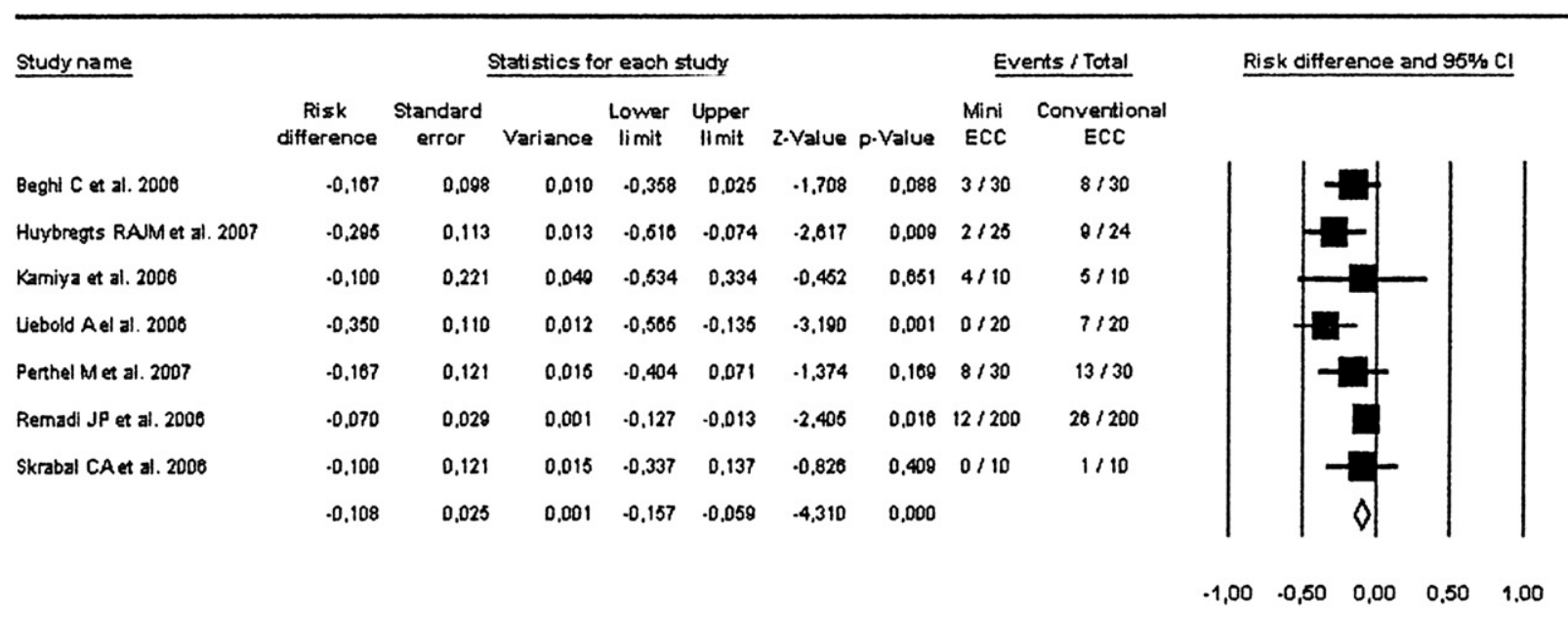

Favours MECC Favours CECC

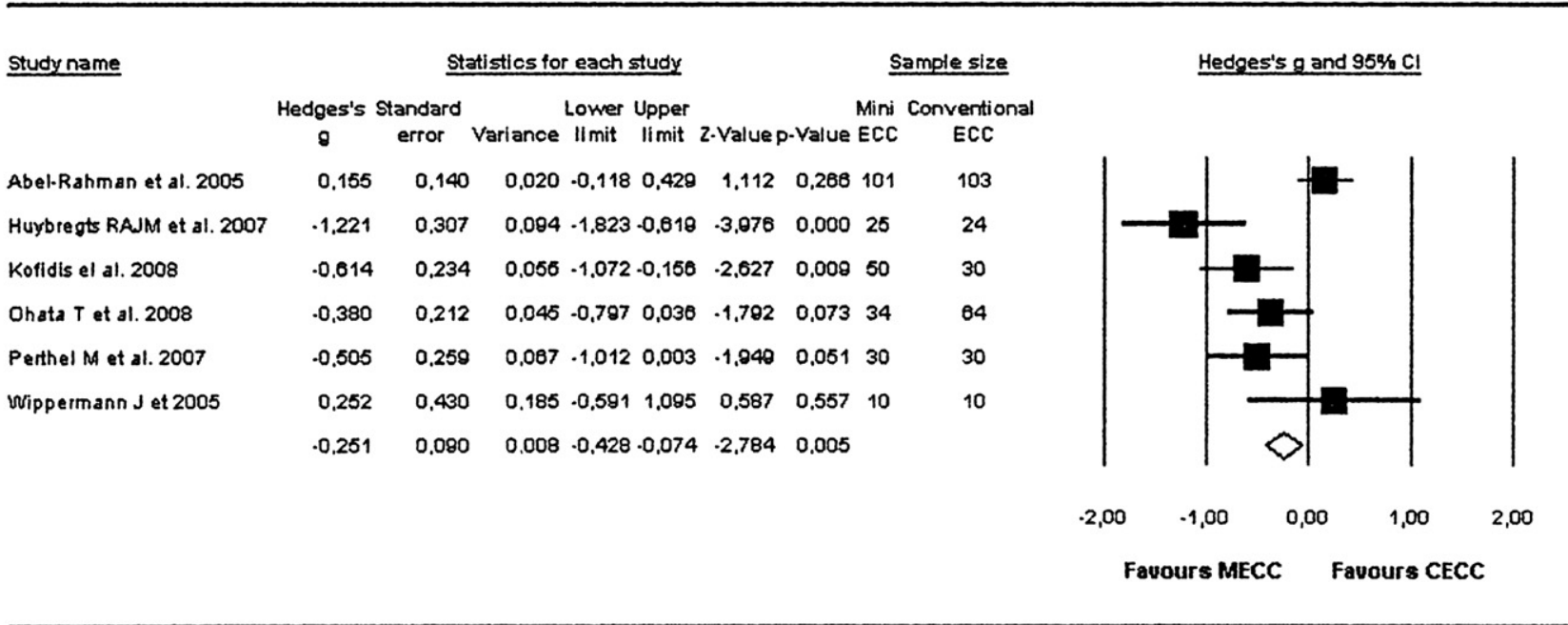

FIGURE 1. Forest plot for RBC transfusion rate (top) and the amount of RBCs transfused per patient (bottom). Squares indicate individual trial, and lozenges indicate pooled summary effect estimate. Risk difference and Hedges'g are displayed on a logarithmic scale. ECC, Extracorporeal circulation; $C I$, confidence interval; $M E C C$, mini extracorporeal circulation; $C E C C$, conventional extracorporeal circulation.

\section{CONCLUSIONS}

This meta-analysis showed mini-ECC reduces postoperative $\mathrm{RBC}$ transfusion in patients undergoing $\mathrm{CABG}$.

\section{References}

1. Koch CG, Li L, Duncan AI, Mihaljevic T, Cosgrove DM, Loop FD, et al. Morbidity and mortality risk associated with red blood cell and blood-component transfusion in isolated coronary artery bypass grafting. Crit Care Med. 2006; 34:1608-16.

2. Huybregts RA, Morariu AM, Rakhorst G, Spiegelenberg SR, Romijn HW, de Vroege R, et al. Attenuated renal and intestinal injury after use of a mini-cardiopulmonary bypass system. Ann Thorac Surg. 2007;83:1760-6.

3. Abdel-Rahman U, Ozaslan F, Risteski PS, Martens S, Moritz A, Al Daraghmeh A, et al. Initial experience with a minimized extracorporeal bypass system: is there a clinical benefit? Ann Thorac Surg. 2005;80:238-43.

4. Beghi C, Nicolini F, Agostinelli A, Borrello B, Budillon AM, Bacciottini F, et al. Mini-cardiopulmonary bypass system: results of a prospective randomized study. Ann Thorac Surg. 2006;81:1396-400.
5. Kamiya H, Kofidis T, Haverich A, Klima U. Preliminary experience with the mini-extracorporeal circulation system (Medtronic resting heart system). Interact Cardiovasc Thorac Surg. 2006;5:680-2.

6. Kofidis T, Baraki H, Singh H, Kamiya H, Winterhalter M, Didilis V, et al. The minimized extracorporeal circulation system causes less inflammation and organ damage. Perfusion. 2008;23:147-51.

7. Liebold A, Khosravi A, Westphal B, Skrabal C, Choi YH, Stamm C, et al. Effect of closed minimized cardiopulmonary bypass on cerebral tissue oxygenation and microembolization. J Thorac Cardiovasc Surg. 2006;131: 268-76.

8. Ohata T, Mitsuno M, Yamamura M, Tanaka H, Kobayashi Y, Ryomoto M, et al. Beneficial effects of mini-cardiopulmonary bypass on hemostasis in coronary artery bypass grafting: analysis of inflammatory response and hemodilution. ASAIO J. 2008;54:207-9.

9. Perthel M, El-Ayoubi L, Bendisch A, Laas J, Gerigk M. Clinical advantages of using mini-bypass systems in terms of blood product use, postoperative bleeding and air entrainment: an in vivo clinical perspective. Eur J Cardiothorac Surg. 2007;31:1070-5.

10. Remadi JP, Rakotoarivelo Z, Marticho P, Benamar A. Prospective randomized study comparing coronary artery bypass grafting with the new mini- 
extracorporeal circulation Jostra System or with a standard cardiopulmonary bypass. Am Heart J. 2006;151:198.

11. Skrabal CA, Choi YH, Kaminski A, Steiner M, Kundt G, Steinhoff G, et al. Circulating endothelial cells demonstrate an attenuation of endothelial damage by minimizing the extracorporeal circulation. J Thorac Cardiovasc Surg. 2006;132:291-6.
12. Wippermann J, Albes JM, Hartrumpf M, Kaluza M, Vollandt R, Bruhin R, et al. Comparison of minimally invasive closed circuit extracorporeal circulation with conventional cardiopulmonary bypass and with off-pump technique in CABG patients: selected parameters of coagulation and inflammatory system. Eur J Cardiothorac Surg. 2005;28:127-32.

Access to The Journal of Thoracic and Cardiovascular Surgery Online is reserved for print subscribers!

Full-text access to The Journal of Thoracic and Cardiovascular Surgery Online is available for all print subscribers. To activate your individual online subscription, please visit The Journal of Thoracic and Cardiovascular Surgery Online, point your browser to http://www.mosby.com/jtcvs, follow the prompts to activate your online access, and follow the instructions. To activate your account, you will need your subscriber account number, which you can find on your mailing label (note: the number of digits in your subscriber account number varies from 6 to 10). See the example below in which the subscriber account number has been circled:

\section{Sample mailing label}

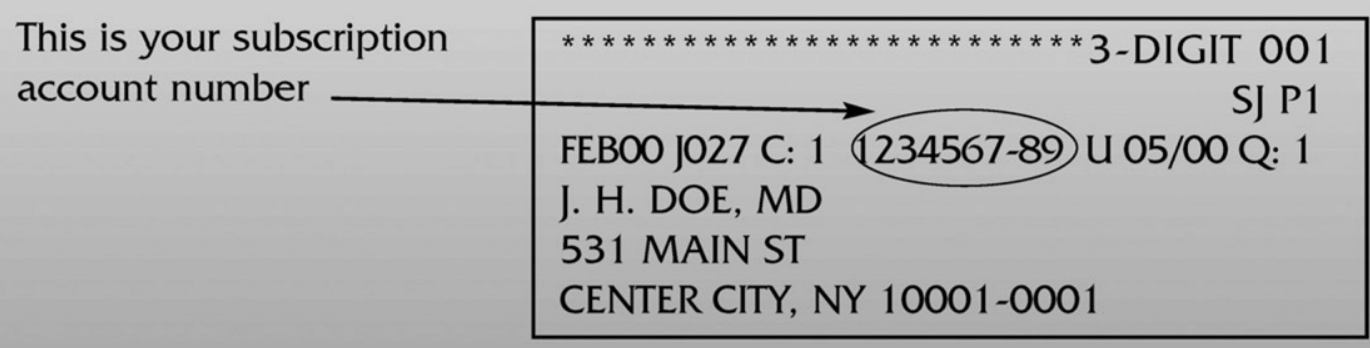

Personal subscriptions to The Journal of Thoracic and Cardiovascular Surgery Online are for individual use only and may not be transferred. Use of The Journal of Thoracic and Cardiovascular Surgery Online is subject to agreement to the terms and conditions as indicated online. 